\title{
ISLAMSKI POGLED NA NEKOREKTNOST U TRGOVINI
}

\section{Sažetak}

U ovom radu ponudeno je jedno videnje nekorektnog odnosa kojima su kupci izloženi od strane trgovaca. Ovdje su predočeni neki od konkretnih i jasnih islamskih stavova po tom pitanju. Navedena je problematika $i$ načini raznih trgovačkih špekulacija, ali isto tako su ponudeni $i$ neki načini za izbjegavanje i otklanjanje takve pošasti. Navedeni su primjeri iz svijeta gdje su načini prijevare mnogobrojni, a svjesni smo i činjenice da ih ima daleko više od onoga što bi moglo da se nade u ovom radu.

Sigurno je da ova tematika zaslužuje još veću pažnju, možda i naučnu konferenciju $i$ izradu daleko većih $i$ značajnijih studija, jer je riječ o stanju društva u kojem se nalazimo i htjeli ili ne, svi smo zahvaćeni nekim vrstama trgovačkih prevara.

Ključne riječi: Kur'an, islam, Muhammed, s. a. v. s., Ebu-Hanife, trgovina, trgovac-kupac, varanje, monopol

\section{Uvod}

U islamskom načinu poslovanja čovjek je važan faktor. On se pojavljuje i kao prodavač i kao kupac. U jednoj takvoj situaciji istina mora uvijek biti prisutna i ničim se ne smije prikrivati ili zanemarivati.

Islam kroz svoje principe i propise želi da spriječi bilo kakvu vrstu izrabljivanja ljudi i nanošenja štete jednih drugima. Veoma dobro je poznat strogi stav u odnosu na zabranu kamate, a osim toga upozorava na ispravno i pošteno upravljanje imovinom zajednice, imovinom jetima i tome slično. Također je osuđena i pohlepa da se što prije i ne birajući sredstva čovjek obogati, ne vodeći računa da li tom prilikom oštećuje ili izrabljuje drugoga.

${ }^{1}$ Islamski pedagoški fakultet u Bihaću. 
Zakidanje prilikom mjerenja je jedan od zabranjenih oblika stjecanja imovine o čemu su Kur'an i hadis izričito jasni.

$\mathrm{Na}$ slijedećim stranicama ćemo ponuditi neke od realnih slika današnjice u pogledu međusobnih odnosa u trgovanju. $S$ obzirom na to da težimo što zdravijem društvu, ovaj rad bi mogao biti makar jedan skromni doprinos u boljem razumijevanju ovog problema i kod nas i u svijetu.

Uzvišeni Allah kaže: $A$ Allah je dozvolio trgovinu, a zabranio kamatu... ${ }^{2} O$ vjernici, jedni drugima na nedozvoljen način imanja ne prisvajajte - ali, dozvoljeno vam je trgovanje uz obostrani pristanak - i jedni druge ne ubijajte! Allah je, doista, prema vama milostiv. ${ }^{3}$

Trgovina je jedan od najvažnijih stubova u ekonomskom razvoju društva. Njen historijski početak je bio u obliku robne razmjene - roba za robu, a kasnije se razvila kroz plaćanje srebrom i zlatom, dok se nije došlo do današnjeg načina poslovanja putem novca i čekova (kartica).

Kupoprodaja, tj. trgovina, u islamu je pohvalna ljudska djelatnost, ali mora ispunjavati određene norme, $u$ što obavezno spada etičnost i odnos bez bilo koje vrste prevare. Svakako da je najveća zabrana u tom pogledu - zabrana poslovanja sa kamatom, kako je navedeno u tekstu Kur'ana, a. š.

Međutim, ovdje ćemo govoriti o drugom obliku zabranjenog sticanja imovinske koristi, gdje se osuđuju prevare. U Kur'anu, a. š., 83. sura nosi ime El-Mutaffifin i njome se ukazuje na problem zakidanja na mjerenju. Islamski učenjaci se razilaze u tome da li ova sura pripada mekanskom ili medinskom periodu objave. Navodeći mišljenja različitih autoriteta po tom pitanju, šejh Ibn-Ašur u svom tefsiru navodi i ono u kojem se kaže da bi ona mogla biti objavljena pred napuštanje Mekke ili odmah po dolasku u Medinu. S tim u vezi Ibn-Ašur citira i Vahidija, koji u svom djelu Povodi objave Kur'ana navodi hadis: Nakon dolaska Vjerovjesnika, s. a. v. s., u Medinu, zatekao je najgore ljude u pogledu zakidanja na mjeri

\footnotetext{
${ }^{2}$ El-Bekara, 275.

${ }^{3}$ En-Nisa, 29.
} 
(vagi), pa je Allah, dž. š., objavio suru 'Vejlun lil mutaffifin' (Teško onima koji pri mjerenju zakidaju). ${ }^{4}$

Jusuf 'Ali navodi da u to spada ono što se prilikom mjerenja i vaganja manje daje, ali u to je uključeno mnogo više. $U$ oba naredna ajeta postaje jasno da je nepravednost u bilo kojem obliku ono što se mora prokleti premalo davati, a previše zahtijevati. Ovo se može ticati trgovine, gdje čovjek sebi više priznaje nego što je spreman da daje; kućne ili poslovne stvari, gdje se zahtijeva više pažnje i uspjeha nego što je sam čovjek spreman da pruži. Sve je to gore nego jednostrana sebičnost. To je dvostruka nepravednost. Ipak, najteže je kada je riječ o vjeri i duhovnom životu.

Kako čovjek može tražiti Allahovu milost i ljubav ako to uskraćuje ljudima u svojoj okolini? Ovdje važi zlatno pravilo, a to je da davanje i uzimanje moraju biti odmjereni. Zapravo je riječ o tome da se u punom obimu mora dati ono što se očekuje od nekoga, svejedno da li se to isto od drugoga očekuje ili ne. ${ }^{5}$

Ljudi na ovom svijetu nose različite vrijednosti. Međutim, islam nas uči da čuvamo samo one vrijednosti koje traži Uzvišeni Allah, naš Stvoritelj, i prema kojima ćemo biti vrednovani i na ovome i na onome svijetu, kao što su iskrenost, poštenje, istinoljubivost, pravednost, dobrota, odgovornost i ustrajnost u dobru.

Zemlje Arapskog zaljeva su razmatrale pitanje varanja u trgovini, te su preko svojih ministarstava dali više uputstava i upozorenja trgovcima. $\mathrm{Ne}$ smije se dati prostora da neko u borbi za što većom i bržom zaradom gazi islamske postulate i učenja.

Stoga je ministarstvo rada i trgovine objavilo rat prevarantima u trgovini kroz sve oblike, a posebno su to istakli na Šestim susretima zemalja arapskog zaljeva za zaštitu potrošača, održanim u državi Katar. To ukazuje na ozbiljnost problema u društvu, sa kojim se treba i pojedinačno i organizirano boriti.

\footnotetext{
${ }^{4}$ Ibn-Ašur, Et-Tahriru vettenviru, 30/187.

${ }^{5}$ Ramo Atajić, Prijevod Kur'ana sa tefsirima, 5/2593.
} 
Navodi se kako je sedamsto osamdeset milijardi dolara bio iznos zarade putem trgovačke prevare u svijetu, od čega $6,4 \%$ u arapskom svijetu. Ahmed ez-Zubejdi iznio je podatak u novinama Eššrerkul-evsat da je samo u Arapskom zaljevu sedam milijardi dolara trgovačkom prevarom zaradeno. $^{6}$

Obostrana saglasnost učesnika u poslovanju znači dogovaranje i jedne i druge strane. Da bi poslovanje bilo legitimno, ta saglasnost je neophodan uslov kojeg treba ispuniti. Zbog toga se nepridržavanje obećanja kojeg je dao jedan učesnik dogovora drugom smatra prevarom i kao takvo je kažnjivo. Stoga je trgovina ispravna samo ukoliko se obavlja uz obostranu saradnju i saglasnost, što znači da, ako nema saglasnosti, nema ni halal trgovine ni halal prodaje.

Islam od nas zahtijeva iskrenost u poslovanju. To znači da, ako si na nekom određenom mjestu kupio malog goluba, kojeg želiš da uzgajaš, a on ti, kad poraste, ne bude golub nego svraka - prevaren si! Takvu prevaru islam prilikom trgovanja i prilikom kupovanja ne odobrava i strogo je zabranjuje. Takvih vrsta prevare ima, a i svi smo sami smo, bar jednom u svome životu, nešto slično doživjeli, jer kupujemo ili prodajemo i bivamo namjerno ili nenamjerno prevareni. Postoji i mogućnost da i mi nekog, nenamjerno, prevarimo. Sve su varijante moguće is naše, a i s druge strane.

\section{Rezultati uspješne trgovine}

O ispravnoj ili dozvoljenoj trgovini i dozvoljenom poslovanju imamo divne primjere i rezultate još iz naše historije, kojima se mi, muslimani, ponosimo. Naime, najmnogoljudnija muslimanska zemlja - ostrvska Indonezija, četvrta zemlja u svijetu po broju stanovnika - postala je muslimanska zemlja ponajviše zahvaljujući ispravnoj trgovini i halal poslovanju. U ovoj državi nisu vođeni ratovi na način da se islam širio sabljom. Islam je u najveću, najmnogoljudniju zemlju došao poštenom trgovinom, saradnjom i dobrim poslovanjem. Kako? Trgovac musliman bi, primjera radi, došao brodom u Indoneziju da proda svoju robu. Jednu

${ }^{6}$ We3rb.net, Šebeketu nahnul-Areb multeka kullel-Areb. 
bi vreću cijenio u jednom iznosu, a druga vreća te iste robe bi bila skuplja. Dakako, svaki kupac bi se tome čudio jer roba izgleda isto, ali su cijene različite.

Tada bi trgovac musliman objasnio zašto je jedna roba jeftinija, a druga skuplja, pa bi rekao da je jednu robu dohvatila vlaga ili je malo pokisla pa je teža, te je ta roba i jeftinija. To poštenje, ta iskrenost tadašnjih muslimanskih trgovaca, duboko je ulazila u uši i srca kupaca.

Svakako ovdje trebamo istaći hadis Allahovog Poslanika, s. a. v. s., koji je rekao: Ko nas vara, ne pripada nama. ${ }^{7}$

Odmaranje uz skrušenost u toku namaza i sveukupan dojam koji su ostavljali tadašnji trgovci - sve to je utjecalo na formiranje svijesti i slike o ljudima koji su im dolazili i sa sobom donosili jedan novi i ljepši način poslovanja. Tako su pošteni trgovci muslimani doprinijeli nastanku najmnogoljudnije muslimanske zemlje na svijetu.

Naš Poslanik Muhammed, s. a. v. s., je, također, bio pošteni trgovac. Tim časnim zanimanjem bavila se i njegova supruga Hatidža, r. a., koju je način Poslanikovog trgovanja zadivio kada ga je angažovala da prati njenu karavanu na putu do Sirije. Poštena trgovina i halal zarada spojila je ova dva draga bića.

I među velikim alimima bilo je trgovca. Jedan od njih je i naš imam u mezhebu kojem mi pripadamo, Ebu-Hanife - fakih, alim, učenjak svoga vremena, imamul 'azam - također je bio trgovac. Njegovo glavno zanimanje koje mu je donosilo prihod, zaradu bila je trgovina. Govoreći o njegovim vrlinama, poznati učenjak Fudajl ibn 'Ijad je između ostalog rekao: Ebu-Hanife je imao mnogo imetka, ali je bio vrlo darežljiv i niko mu nije dośao sa svojom potrebom a da mu to nije ispunio. On je svake godine slao posebnu karavanu u Bagdad $i$ kada bi se njegovi ljudi vratili sa robom $i$ hranom, on je izdvajao hranu i odjeću učenjacima za cijelu godinu, a ono sto mu je ostalo u novcu od te zarade, dao bi im i rekao: 'Neka vam se nade

${ }^{7}$ Muslim; 102. 
za vašs potrebe i ne zahvaljujte nikom osim Allahu, jer ja smatram da mi Allah preko vas daje bereket $\mathrm{u}$ trgovini. ${ }^{18}$

Umjesto kadiluka, Ebu-Hanife je izabrao drugi način zarade i finansiranja sebe i svoje porodice. Naime, on je bio jedan od rijetkih učenjaka koji se hranio trudom vlastitih ruku, baveći se poštenom trgovinom, a nije živio od nauke niti je kao učenjak uzimao pare i platu iz državne blagajne. Njegov unuk Omer ibn Hamad ibn Ebi-Hanife rekao je: Ebu-Hanife je bio trgovac svilom i njegov ducan je bio poznat $u$ Kufi, nalazio se u kuci Amra ibn Hurejsa. ${ }^{9}$

Slično dešavanje zabilježeno je i jednom drugom prilikom. Ono što je bilo zanimljivo u njegovoj trgovini, kako je djelovao, koliko je bio pošten, kako i koliko dobar, graniči sa fantazijom u odnosu na današnje vrijeme u kojem živimo. Jedne prilike njegov radnik prodao je jedan ogrtač. Dolazi Ebu-Hanife i pita ga gdje mu je onaj ogrtač. On odgovara da ga je prodao. Nakon toga ga Ebu-Hanife pita je li kupcu napomenuo da na tom ogrtaču ima jedna mahana, feler, jer onaj iznos para koliko je iznosio bio je zbog te mahane, nedostatka. Čovjek reče da je zaboravio to da kaže. Ebu-Hanife ga šalje da ga brzo potraži i dovede nazad. EbuHanife ostaje u dućanu da prodaje, čeka dok ovaj hoda po pijaci, traži ne bi li našao onog čovjeka što je kupio ogrtač.

Kad ga je uspio pronaći, dovodi ga pred kadiju koji uzima od njega ogrtač, raširi ga i kaže da mu je cijena bila mnogo veća, ali je jeftiniji upravo zbog greške koju na sebi ima, te ako je i dalje voljan za te pare da ga nosi, neka ga uzme nazad, a ako neće da ga uzme nakon što je vidio nedostatak na njemu, dobit ćeš svoj novac nazad i ostaviti ogrtač. Ovakav način trgovine i ovakvo poštenje može samo zadiviti kupca. ${ }^{10}$

U ovom postupku praktično se pokazuje da'vetska metoda čovjeka koji živi islam i poziva islamu kroz koji svi ljudi u svojoj svakodnevnici prolaze.

\footnotetext{
${ }^{8}$ El-Hatib el-Bagdadi, Tarihu Bagdad, 13/340.

9 Šemsuddin Ez-Zehebi, Sijeru el-'alam en-nubela', 6/394.

${ }^{10}$ Ebul-Hadždžadž el-Mizzi, Tehzibul-kemal, 29/487
} 
Poštenje cijene i prijatelj i dušman. U Londonu ima dosta mjesta gdje se obavlja namaz. Imam jednog londonskog džemata ispričao je slučaj kada je koristio autobuski gradski saobraćaj od stana do svoje džamije. Šofer koji vozi na toj liniji duže je vrijeme na tom radnom mjestu, pa je tako i zapamtio na kojoj stanici imam ulazi i gdje izlazi. A znao je da je tu mesdžid. Jedne prilike dok je imam kupovao kartu, vozač, koji je uz to naplaćivao karte, vrati mu pet penija više kusura. Tako je efendija sjeo te kartu i kusur koji je uzeo od šofera stavio u svoj džep, ali nešto mu nije dalo mira i dok je sjedio pogledao je ponovo sadržaj džepa, izračunao i primijetio da mu je vraćeno pet penija više. Nastavio se voziti autobusom i kada je došao pred svoju džamiju, izvadio je onih pet penija i rekao kondukteru da mu je dao viška novca prilikom vraćanja kusura, da to nije njegovo. Vrata autobusa su se otvorila i efendija je krenuo da izađe. Tada ga je šofer zaustavio i okrenuvši se putnicima rekao da on nije slučajno dao taj višak efendiji, nego namjerno. Dodao je da ga on vozi u džamiju svaki dan, pa je želio znati šta to on radi tamo u toj džamiji, uči li ljude poštenju, bezobrazluku ili iskrenosti. Imam je tada zaplakao, rekavši da mu zamalo vjera ne propade zbog njegovih pet penija. I ovo je snaga vjere, snaga poštenja. Tako se dobivaju simpatije kod ljudi drugih svjetonazora, koji ne gledaju na ovaj svijet kao što mi gledamo.

Kada je u pitanju pouzdanost u poslovanju, to je jedna od najbitnijih etičkih principa u transakcijama. Znači, ako si pouzdan poručuješ, naručuješ robu, pa se onda osloniš na Allaha, dž. š., i ona dođe na vrijeme i treba da bude uredu.

Islam od nas, također, zahtijeva i plemenitost u poslovanju. Znači, učesnik u poslovanju mora da bude blag i plemenit prilikom ugovaranja poslova. Stoga, ko god prodaje, kupuje ili potražuje svoj dug, mora to činiti na plemenit i uljudan način. Svi smo mi često u nekim dugovanjima. Vjernik bi najradije onom kome je dužan odmah vratio, jer nije lahko spavati pod dugom. Dešava se da nije u mogućnosti brzo vratiti dug, pa ga obuzme stid zbog toga što ne može na vrijeme otplatiti, a i taj stid je dio imana. Ako je onaj kome si dužan dobar prijatelj pa osaburi, zna da nemaš, jer kad budeš imao ti ćeš vratiti, on pokazuje plemenitu osobinu koju Uzvišeni Allah voli. 
Slijedeća vrlina kojoj islam pridaje važnost jeste čestitost ili časnost. Svaki učesnik u poslovanju mora da ispunjava obaveze iz ugovora i usmena obećanja, jer su time natjerani imperativom, Allahovim, dž. š., riječima iz sure El-Maide, gdje kaže:

O vjernici čvrsto se držite zadate riječi - ugovora! ${ }^{11}$, a data riječ može biti u pisanoj i usmenoj formi, tj., ako se kaže vratit ću, posudit ću, kupit ću $\mathrm{i}$ tome slično, treba stajati iza toga. Radije ne treba obećavati ako se ne može ispunjavati.

Kad govorimo o pravima radnika, jedna uobičajena fraza kod nas je da znamo da je lijepo platiti radniku njegov trud u određenom vremenu, shodno Poslanikovom, s. a. v. s., hadisu kojeg bilježi Ibni Madže: Isplatite zaradu najamniku prije nego mu se znoj osuši na čelu. To je jedan od najljepših načina, kada je čovjeku najslađa zarađena para.

Kada je riječ o obmani i prevari pri kupoprodaji i poslovanju, treba znati da je to šerijatski zabranjeno. Ali da je ima - ima je. Time se gubi pozitivna slika o čovjeku trgovcu koji takvim potezima ruši svoj ugled i zaslužuje da mu se njegovoj robi više ne primakne, a Allah, dž. š., takvima oduzima bereket, nafaku. Jedno od Allahovih lijepih imena je Er-Rezak, Onaj koji opskrbljuje, jer Allah, dž. š., daje nafaku ljudima odakle se i ne nadaju, kako kaže kur'anski ajet: (...) a onome koji se Allaha boji, On će izlaz naći i opskrbit će ga odakle se i ne nada; onome koji se u Allaha uzda, On mu je dosta... ${ }^{12}$

\section{Uzroci varanja}

Velika trka na polju trgovine i borbe za što veću i bržu zaradu uzrokovala je i pojavu mnogobrojnih prevara. Isto tako, na tržištu se pojavljuje sve više robe od raznih proizvođača i različite kvalitete. Ponuda i potražnja su učinili svoje, tako da mnogi brzom proizvodnjom i izbacivanjem na tržište, zapostave kvalitetu robe.

Najčešći razlozi u varanju prilikom trgovanja su slijedeći:

\footnotetext{
11 El-Maide, 1.

12 Et-Talak, 2-3.
} 
- nedostatak vjerske svijesti i straha od Boga,

- slabost u vjeri i nedostatak domoljublja (jer oštećuje i svoju domovinu),

- davanje prednosti ličnoj koristi u odnosu na korist zajednice,

- opća neodgovornost,

- egoizam, samoljublje,

- želja za što bržom zaradom. ${ }^{13}$

Prilikom trgovine ne preporučuje se zaklinjanje, (osim ako to bude bilo neophodno, kako se ne bi prizivao Allah na sve što se kupuje i prodaje), kao što su riječi Boga mi, Allaha mi i tome slično. Nemojmo to sebi dozvoliti, jer kada radimo svoj posao dobro, kad radimo iskreno, pošteno, čistog obraza, onda posljedice mogu biti samo pozitivne, kako na nas koji radimo pošteno, tako i na one sa kojima radimo.

Vrlo je važno napomenuti i pitanje nadmetanja. Muhammed, s. a. v. s., je zabranio nadmetanje u trgovini i zarukama. Ako se zna da su momak i djevojka zaručeni, treća osoba nema pravo da se upliće i da razvrgava te zaruke. Dok su oni u takvoj vezi, haram je, zabranjeno je rušiti tu vezu koja još uvijek traje. To je isto i u trgovini zabranjeno, kao kada nešto kupuješ i još uvijek se sa trgovcem dogovaraš, a treća osoba ulijeće u vaš razgovor i nudi više. To je haram. Treća osoba ne smije da upada u trgovinu između dvije osobe sve dok to one ne završe. Tek ako se nisu dogovorili, dakle kupac je odustao, onda se treća osoba može priključiti i dogovarati cijenu.

U jednom hadisu koji se nalazi u zbirkama Buharije i u Muslima stoji: Trgovac $i$ kupac imaju pravo izbora (da prihvate ili ne prihvate kupoprodaju), sve dok se ne rastanu, pa ako su bili iskreni $i$ medusobno sve razjasnili, bit će obojici bereket u njihovoj trgovini. A ako su šta jedan drugom prikrili ili slagali, umanjit će im se bereket $u$ njihovoj trgovini. ${ }^{14}$ To znači da će Allah, dž. š., izbrisati bereket ako bilo koja od tih strana

\footnotetext{
${ }^{13}$ www.benisidel.info

${ }^{14}$ Buharija, 2079. i Muslim, 1532.
} 
slaže ili podmetne, a ako su pošteni onda Allah, dž. š., daje bereket i zadovoljstvo i jednome i drugome.

\section{Sloboda izbora na mjestu ugovora}

Sloboda izbora na mjestu ugovora utemeljena je riječima Poslanika, s. a. v. s.: Kupac i prodavać imaju pravo na slobodan izbor sve dok ne odu sa mjesta ugovora... 15

Kupac i prodavač imaju pravo odustati od ugovora sve dok su fizički zajedno na jednom mjestu ili dok zajedno putuju, ako ugovor sklapaju na putovanju, ili dok se zajedno kreću ka istom odredištu. Sloboda izbora u kući traje sve dok jedna strana ne iziđe iz kuće, sloboda izbora u prevoznom sredstvu (autu, avionu, brodu) traje do stizanja na odredište ka kojem se kreću kupac i prodavač, sloboda izbora u telefonskom razgovoru traje sve do okončanja razgovora i sl. O nestanku povjerenja, Poslanik, s. a. v. s., nas je davno obavijestio. Rekao je da će ljudi tragati za povjerljivom osobom i da će se prepričavati kako tu i tu ima povjerljiv čovjek. Rekao je: Ljudi će trgovati jedni sa drugima, a gotovo da niko do njih neće biti povjerljiv i korektan. Prepričavat će se: 'U tom $i$ tom mjestu ima povjerljiv čovjek.' ${ }^{16}$

Kupac ima slobodu izbora zbog eventualnog tedlisa ${ }^{17}$ (prijevare, obmane, skrivanja mahane ili predstavljanja robe u lažnom svjetlu) da, ukoliko to želi, odustane od trgovine. Mudellis je onaj koji skriva pravo stanje svjesno i namjerno daje ljudima pogrešnu predstavu o nečemu. Preneseno na pitanje o kojem govorimo, tedlis je skrivanje prave kvalifikacije robe, predstavljanje robe onakvom kakva ona nije u stvarnosti i skrivanje njenih mahana.

Zabrana tedlisa i dozvola prekida trgovačkog ugovora zbog njega uzeta je iz riječi Poslanika, s. a. v. s.: Ne zadržavajte mlijeko u (vimenu) devi $i$ bravčetu (ovci), jer onaj ko je kasnije kupio ima pravo da odabere što mu

\footnotetext{
15 Ibid.

${ }^{16}$ Buharija, 6132 i Muslim, 143.

17 Teufik Muftić, Arapsko-bosanski rječnik, str; 451
} 
bude bolje od dvoje: kada je pomuze, ako hoće zadržat će je, a ako hoće, vratit će je (prodavaču) sa sa'om datula. ${ }^{18}$

Kao dokaz može poslužiti i slučaj koji se odgodio u vrijeme Poslanika,s.a.v.s.On je prošao pored čovjeka koji je prodavao pokislu pšenicu, $s$ tim da je na vrh posude stavio suhu pšenicu kako se ne bi primijetilo kakav je ostatak. Uvukao je ruku i primijetio da je pšenica vlažna i upitao ga je u čuđenju:

- Šta je ovo vlasniče prenenice?!

- Pokisla je, Poslaniče, zbunjeno će on.

- A što vlažnu pšenicu nisi onda stavio na vrh, da ljudi vide da je pokisla? Ko nas vara - nije od nas. ${ }^{19}$

\section{Ihtikar ili monopol nad robom}

Analizirajući definicije koje su za monopol dali islamski klasici iz kruga različitih pravnih škola i savremenu definiciju monopola, uočavamo bitne razlike. Monopol je kod hanefijskih pravnika skladistenje brane iščkivajući njeno poskupljenje; kod malikijskih pravnika skladistenje robe i obilazak različitih tržišta u nadi da ce se ostvariti profit; kod šafijskih pravnika skladistenje hrane kupliene u vrijeme skupoce, makar ona bila $u$ formi datula i suhog grožda, kako bi se izvršila njena prodaja po još većoj cijeni.

To znači da su islamski učenjaci jedinstveni u osudi ihtikara, tj. skrivanja robe, koja bi se potom skupo prodala u vrijeme nestašice. Kako vidimo, to se posebno odnosi na robu koja je od životne važnosti - prehrambeni proizvodi, dok se luksuzne stvari, kao što su med, maslo, meso i voće isključuju iz toga. ${ }^{20}$

\footnotetext{
${ }^{18}$ Buharija, 2148 i Muslim, 1515.(Mudd kod Hanefija iznosi 1,032 litra ili 815 grama, a kod ostale trojice imama u mezhebima mud iznosi 0,687 litara ili543 grama. Vidi: Kalhadži, $M u^{\prime} d \check{z} e m$ lugatil-fukaha, str. 314.)

19 Muslim, 102.

${ }^{20}$ Ez-Zuhajli, El-Fikhul-islami ve edilletuhu, 3/585.
} 
Ulema se, također, slaže da se zabrana ihtikara odnosi i na hranu za stoku, ${ }^{21}$ jer postoji opasnost da umru od gladi, ukoliko vlasnik ne može da kupi preskupu hranu. Uočljivo je također da se samo skladištenje robe nadajući se njenom poskupljenju, smatra monopolom, dok skladištenje iz nekog drugog razloga nije monopol. Ali svakako su specifične po tome što ne obuhvataju većinu formi u kojima se monopol pojavljuje u današnje vrijeme.

\section{Primjeri varanja u procesu trgovine}

Najčešće se da primijetiti da se varanje obavlja na slijedeće načine:

- umanjenje mjere u težini, metraži ili litraži - u ovome se čini nepravda prema ljudima i uzima imovina na nedozvoljen način;

- nedostatak neke od materija u pojedinim lijekovima zbog kojih čovjek, korisnik, može još više da strada;

- prodaja robe $s$ istekom roka trajanja, čime se dovodi do mogućnosti trovanja osobe koja to konzumira;

- stavljanje na robu etikete neke poznate i svjetski poznate firme, a porijeklo robe je iz neke slabe firme i druge zemlje;

- prodaja mineralne vode, a koja zapravo u sebi ne sadrži sve elemente i kvalitete koji su ispisani na sadržaju i sastavu vode;

- prodaja konzervirane robe ili pakovane na neki drugi način, ali bez obilježavanja njenog roka trajanja;

- nenavođenje porijekla robe ili nejasno označena roba;

- prodaja lošeg (ili pokvarenog) sjemena, što može utjecati da propadne godišnja sjetva i prouzroči veliku štetu po kupca sjemena. ${ }^{22}$

\footnotetext{
${ }^{21}$ Ibid, 3/386.

${ }^{22}$ www.benisidel.info
} 


\section{Neke od šteta čiji je uzrok varanje u trgovanju:}

- takvima Allah, dž. š., neće dove primati, niti će im dati bereketa u imetku i životu,

- ko to čini, otkriva da u svome srcu ima nedostatak imana,

- pravi sebi put u Džehennem,

- ljudi će ga zamrziti i izbjegavati ga,

- otkriva svoju pokvarenost u duši,

- Poslanik, s. a. v. s., ga se odriče (prema navedenom hadisu na ovu temu),

- varanje u islamskom društvu daje ružnu sliku islama u očima nemuslimana,

- varanje utječe na opću negativnu klimu u društvu,

- stiče se haram zarada lažnim zaklinjanjem ili varljivom robom,

- varanje je izdaja emaneta (povjerenja) i gubitak za ummet,

- varanjem se sprečava mogućnost postizanja korisne nauke.

\section{Načini liječenja ovog problema}

- Kako bi se stalo na kraj raznim vrstama prevara u trgovini, potrebno bi bilo utjecati na cjelokupno društvo, kako na trgovca tako i na kupca. Trgovac bi morao biti upoznat sa šerijatskim propisima vezanim za oblast trgovanja;

- Potrebno je i to da sami kupci ukažu trgovcu ako primijete neku vrstu prevare, jer će tako saznati da li je varanje bilo namjerno ili nesvjesno, kao što se često dešava kod, primjera radi, vraćanja kusura prilikom plaćanja. Ukoliko se ispostavi da je varanje bilo svjesno i namjerno, onda treba upoznati nadležne organe i institucije za zaštitu potrošača, jer bi se tako, ako sam trgovac ne želi ispraviti svoju grešku, bar spriječio nastavak takvih radnji. Svakako da je najbolje da se sam trgovac osvijesti i uspostavi trgovanje na principima iskrenosti, poštenja i bogobojaznosti; 
- Istina je da postoji i veliki broj poštenih trgovaca kojima je varanje strano, jer su sigurni da Svemogući Allah sve vidi i ništa Mu ne može promaći. Među takvim trgovcima svakako da ima i nemuslimana koji se drže karakternog i poštenog poslovanja. Ovakvi trgovci trebaju biti uzor ostalim partnerima u trgovačkim poslovima, a za dobrobit cijelog društva;

- Snaženje vjerskog poticaja kod ljudi, jer ljudska srca ispunjena ljubavlju prema Allahu neće dati prostora za varanje;

- Odgajanje mladih još u djetinjstvu na principima povjerenja i odbijanje svega što je negativno, što uključuje i varanje;

- Nastojati da se prevaranti zakonski kazne, uz onemogućavanje da se ponovo povrate krivom poslovanju;

- Obrazovati kupce na određene načine kako bi izbjegavali kupovinu kod trgovaca - varalica, čime će opasti njihova zarada.

\section{Zaključak}

Istina je da živimo u vremenu brzog življenja, a ta šejtanska brzina nas može odvesti na krivi put. Pišući ovaj rad imali smo za cilj da bacimo svjetlo na pojavu koja je sve raširenija u svijetu. Neke zemlje su to ozbiljno shvatile, te su donijele i neke zakonske odredbe kako bi spriječile malverzacije i nekorektnost u trgovini.

U ovom radu iznesena je problematika varanja i monopola u trgovanju, gdje su, opet, najčešće ugroženi siromašni slojevi društva, a bogati samo više gomilaju svoje bogatstvo. Veoma malo je među ovim drugima onih koji razumiju siromašnije i žele im pomoći.

Pohlepa i žeđ za bogatstvom je jedna vrsta bolesti kojoj su takvi ljudi izloženi. Islam nudi konkretna rješenja protiv tih problema, prvenstveno kroz strogu zabranu kamate, a potom i kroz zabranu svih drugih vrsta prevare i izrabljivanja ljudi.

To znači da vraćanjem na principe iskrenosti, poštenja i pravde, možemo očekivati poboljšanje stanja u današnjem iskvarenom društvu. 
Jedan od zaključaka ovog rada može biti i poziv na oprez prilikom svih vrsta transakcija među ljudima, makar one bile i veoma male. Bez obzira na to da li je riječ o banalnoj prevari (npr. sipanju vode u mlijeko), ili kupovini kuća, stanova ili automobila, čovjek uvijek treba biti na oprezu.

Biti prevaren je nešto što u duši prevarenog unosi nemir i žal zbog tog čina, dok prevaranti uz pomoć šejtana - pomagača likuju zbog tog svog uspjeha.

Vjera u odgovornost pred Bogom pomoći će nam da se odupremo i najmanjoj želji ili strasti za prevarom.

$\mathrm{Na}$ kraju bih ponovio prijedlog da se organiziraju naučne konferencije $\mathrm{u}$ cilju suzbijanja i sankcionisanja svih vrsta prevara.

\section{Literatura:}

1. Besim Korkut, Kur'an s prijevodom značenja na bosanski jezik

2. Ebul-Hadždžadž el-Mizzi, Tehzibul-kemal

3. El-Hatib el-Bagdadi, Taribul-Bagdad

4. Muhammed Tahir Ibn-Ašur, Tefsirut-tahriri vet-tenviri, Darut-tunisijje linnešr,Tunis, 1984.

5. Muhammed b. Ismail el-Buhari, Sahihul-Buhari, grupa prevodilaca, Sarajevo, 1430. god. po H. (2009.)

6. Muslim, Sahihul-Muslim, Muslimova zbirka hadisa - sažetak, grupa prevodilaca, El-Kalem, Sarajevo, 2004. Godine

7. Ramo Atajić, Prijevod Kur'ana sa tefsirima, Bemust, Sarajevo

8. Šemsuddin Ez-Zehebi, Sijeru el-'alam en-nubela'

9. Teufik Muftić, Arapsko-bosanski rječnik, Sarajevo. 1997.

10. Ez-Zuhajli, El-Fikhul-islami ve edilletuhu, Dimešk, 1989. 
Izet Terzic, $\mathrm{PhD}$

\section{ISLAMIC VIEW ON THE INCORRECTNESS IN TRADE}

\section{Summary}

This paper has offered one opinion regarding the form of mistreatment which imposed on the customers by certain merchants.

We have presented some concrete and clear Islamic position on this issue. Beside mentioning these problems and the methods of various trade speculations, we also offered some ways for avoiding and eliminating of such a scourge.

We have mentioned are examples from around the world where cheating are very diverse, and we are aware of the fact that there are far more than what might be found in this paper.

It is certain that this issue deserves even more attention, and perhaps a scientific conference and writing a much larger and important study, because this is the state of society in which we live and where we all are affected by some type of commercial fraud, with or without our will.

KEY WORDS: Quran, Islam, Muhammad, p.b.h, Abu Hanifa, trade, merchant-customer, cheating, monopoly 


\section{الأستاذ الدكتور عزت ترزيتش بr}

\section{نظرة الإسلام إلى التعامل غير المقبول في التجارة}

\section{الخلاصة}

يقدم هذا البحث نظرة للتعامل غير المقبول والذي يعامل به التجارُزبائههم على أساسـه.

يحتوي البحث على عدد من الآراء الإسلامية الواضحة والمحددة حول هذه

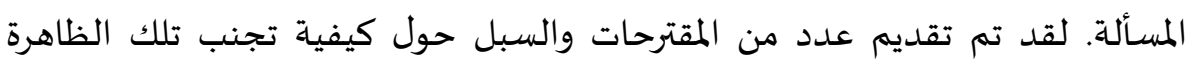

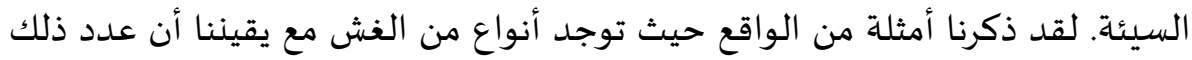

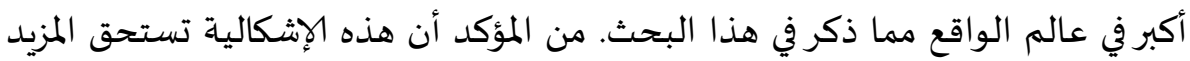

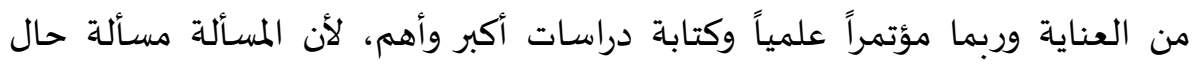

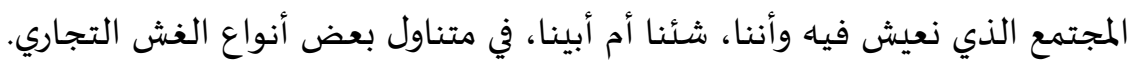

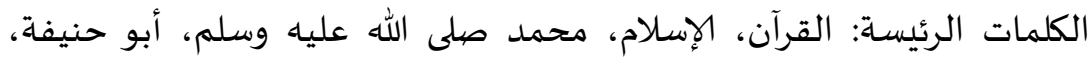

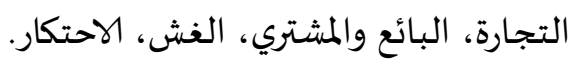

